\title{
Study of struvite crystallization from fertilizer industry wastewater by using fluidized bed reactor
}

\author{
Warmadewanthi $^{{ }^{*}}$ and Yahdini Fitri Rajabi Bachtiar ${ }^{1}$ \\ ${ }^{1}$ Department of Environmental Engineering, Institut Teknologi Sepuluh Nopember, Surabaya, \\ Indonesia
}

\begin{abstract}
The fertilizer industry produces wastewater containing 9815 $\mathrm{mg} / \mathrm{L}$ of phosphates and $2558 \mathrm{mg} / \mathrm{L}$ of ammonium, which may cause eutrophication if untreated. Wastewater that contains a large amount of phosphate can become a potential source of phosphate which is depleting on a global scale. Fluidized bed reactors are an effective method of phosphate recovery by producing struvite crystals. This study evaluates the effects of the upflow velocity on the performance of the fluidized bed and analyzes the struvite that is recovered. The experiment was conducted in laboratory scale at room temperature. Fertilizer industry wastewater and $\mathrm{MgCl}_{2}$ were added into fluidized bed reactors at $0.014,0.019$, and 0.0024 $\mathrm{m} / \mathrm{s}$ upflow velocity. The operating $\mathrm{pH}$ was $8.5 \pm 0.2$. Inside the reactors was sand No. 30/60 that worked as a seed material. The result showed that fluidized bed reactors could recover phosphate up to $73 \%$ and ammonium up to $57 \%$ at $0.014 \mathrm{~m} / \mathrm{s}$ upflow velocity. Increasing the upflow velocity at intervals of $0.005 \mathrm{~m} / \mathrm{s}$ could decrease the phosphate recovery by $1-2 \%$ and ammonium by $3-4 \%$. SEM-EDX analysis showed that products were attached to the seed material, which contained $\mathrm{N}, \mathrm{P}, \mathrm{Mg}, \mathrm{O}, \mathrm{Ca}, \mathrm{F}$, and $\mathrm{Si}$ as the main constituent elements. The recovered products contain $60.2 \%$ of struvite, which mainly works as a slow released fertilizer.
\end{abstract}

\section{Introduction}

Fertilizers are organic or inorganic, either synthetic or natural materials that are added to the soil to provide important nutrients for plant growth [1]. However, in the process of fertilizer production, the fertilizer industries produce wastewater that has a high level of ammonium and phosphate [2]. A high concentration of phosphate in wastewater will be very dangerous if disposed directly to the environment, because it may cause eutrophication in surface water [3]. Eutrophication is an explosive growth of aquatic plants and algae due to the excessive content of nutrients, especially phosphate and ammonium, in water bodies. Some of the negative impacts of eutrophication are: a bad appearance of the water including odor and taste decreased dissolved oxygen levels at night and reduced light

\footnotetext{
*Corresponding author: warma@its.ac.id
} 
penetration in water [4]. Surface water that has undergone eutrophication may cause aquatic death all over the world [5]. Wastewater treatments through recovery have more advantages than just eliminating the polluting content of wastewater. Phosphate recovery from wastewater is an economical and long-term solution due to problems with the availability of phosphate, which will run out within 60-70 years. Therefore, a study conducted over the next 10-25 years must be centered on recovery rather than elimination [6,7].

Several studies were done to utilize the phosphate and ammonium that are contained in wastewater by producing struvite crystals $\left(\mathrm{MgNH}_{4} \mathrm{PO}_{4} \cdot 6 \mathrm{H}_{2} \mathrm{O}\right)$. Wastewater that provides a high level of $\mathrm{N}$ and $\mathrm{P}$ is an effective source of struvite recovery [8]. Based on Rahaman [9], the chemical reaction of struvite formation is:

$$
\mathrm{Mg}^{2+}+\mathrm{NH}_{4}{ }^{+}+\mathrm{PO}_{4}{ }^{3-}+6 \mathrm{H}_{2} \mathrm{O} \rightarrow \mathrm{MgNH}_{4} \mathrm{PO}_{4} \cdot 6 \mathrm{H}_{2} \mathrm{O}
$$

Struvite is becoming an interesting means of phosphate recovery because it contains cheap $\mathrm{N}$ and $\mathrm{P}$ nutrients for fertilizer industry raw materials [9]. Struvite is a crystalline mineral made of magnesium, ammonium, and phosphate in the same molar concentration in alkaline condition [10]. Struvite can also be used as fertilizer, with more advantages than the usual fertilizers. These advantages are as follows: struvite can release nutrients at a slower rate so it can allow plants to absorb nutrients before they are washed away, decreased eutrophication because fewer nutrients are leached, saving the use of fertilizers, essential nutrients such as phosphate $(\mathrm{P})$, nitrogen $(\mathrm{N})$ and magnesium can be absorbed simultaneously, without using any other artificial components, and it has 2-3 times lower heavy metals impurities than commercial fertilizers [11].

The important thing in phosphate recovery is the ease of the application although the sources are wastewater, and research shows the easiest way is through crystallization [12]. The advantages of struvite formation through crystallization are that the struvite crystals that are produced can be directly used as a fertilizer [13]. The crystals are formed through supersaturation, nucleation and crystal growth [14]. Supersaturation of a solution depends on each element constituting the crystals, which in this case are magnesium, phosphate, and ammonium. Nucleation is the initial process of struvite crystallization that will be grown in the crystals growth step until the equilibrium phase is obtained [15].

Several continuous reactors have been used in phosphate recovery through struvite formation, including the CSTR (continuous stirring tank reactor), and FBR (fluidized bed reactor). The FBR can perform better because it can recover up to $80-95 \%$ of phosphate, while the CSTR is only capable of up to $80-85 \%$ of phosphate recovery [16-19]. Struvite crystallization kinetics shows that struvite formation is best in a high mixing energy condition, and FBR has the excellent mixing energy required [20]. Some factors that can affect the struvite crystallization process in FRB are the degree of saturation of the solution, the flow rate through the reactor, stirring, molar ratio, $\mathrm{pH}$, impurities ions, and seed materials $[2,10,12,21]$. The utilization of struvite as a fertilizer is highly dependent on the size of the crystal particles. Particle size is one of the important characteristics in fertilizers, where the larger the particle size, the longer it persists in the soil so that it may increase the nutrient uptake by plants [22]. Two important methods to increase crystal particles diameter are by increasing secondary nucleation and the reaction time. There are two ways to increase secondary nucleation by using crystals seeding and increasing the flow rates [8].

\section{Materials and methods}

\subsection{Sample preparation and seed material}

The sample was taken from the effluent of fertilizer industry wastewater that was treated with electrodialysis reactors to reduce the impurities ions, such as fluoride and calcium. The 
magnesium source used was $\mathrm{MgCl}_{2}$. The ratio of $\left[\mathrm{Mg}^{2+}\right]:\left[\mathrm{PO}_{4}{ }^{3-}\right]$ was $1.5: 1$. The $\mathrm{pH}$ of the wastewater was maintained at $8.5 \pm 0.2$ by adding $\mathrm{NaOH}$ solution made from industrial $\mathrm{NaOH}$ flakes. The characteristics of the wastewater could be seen in Table 1 .

Table 1. Characteristics of wastewater.

\begin{tabular}{|c|c|}
\hline Parameter & Concentration $(\mathbf{m g} / \mathbf{L})$ \\
\hline $\mathrm{pH}$ & 8 \\
\hline Magnesium & 0 \\
\hline Phosphate & 9815 \\
\hline Ammonium & 2558 \\
\hline Fluoride & 220 \\
\hline Calcium & 137.49 \\
\hline TSS & 9.66 \\
\hline COD & 100 \\
\hline Silica & 19.80 \\
\hline
\end{tabular}

Sand was selected as the seed material to enhance the secondary nucleation or crystals growth. The sand used was No. 30/60 mesh, that had already been cleaned using tap water and dried in an oven at $105 \mathrm{C}$ for 24 hours. Sand has inert characteristic, having good resistance in high alkalinity solution, and good fluidization behavior. Mesh no. 30/60 was chosen because of its good fluidization behavior, good sand circulation, and good turbulence flow [23]. The characteristics of sand as seen in Table 2.

Table 2. Characteristics of seed materials.

\begin{tabular}{|c|c|c|}
\hline Parameter & Unit & Scale \\
\hline Specific gravity & - & 2.81 \\
\hline Mean diameter & $\mathrm{mm}$ & 0.40 \\
\hline Minimum fluidization velocity $\left(\mathrm{v}_{\mathrm{mf}}\right)$ & $\mathrm{m} / \mathrm{s}$ & 0.0021 \\
\hline Terminal velocity $(\mathrm{vt})$ & $\mathrm{m} / \mathrm{s}$ & 0.0243 \\
\hline
\end{tabular}

\subsection{Experimental set-up}

An FBR was set up as a struvite crystallizer. There were three main parts, i.e. inlet, chamber 1 , and chamber 2 . The inlet part consists of a wastewater tank, and $\mathrm{MgCl}_{2}$ solution tank pumped into the reactor by using a diaphragm pump that has a flow adjuster and flow meter displayed. Chamber 1 was an acrylic tube with $1.5 \mathrm{~m}$ length and $5 \mathrm{~cm}$ in diameter, equipped with a pressure gauge along the tube. Inside the chamber, $1 \mathrm{~kg}$ of seed material was used for each treatment. Chamber 2 was also made of an acrylic tube with $0.25 \mathrm{~m}$ length and $10 \mathrm{~cm}$ in diameter and was used to prevent seed material flowing into the outlet. The FBR scheme used is detailed in Fig. 1. 


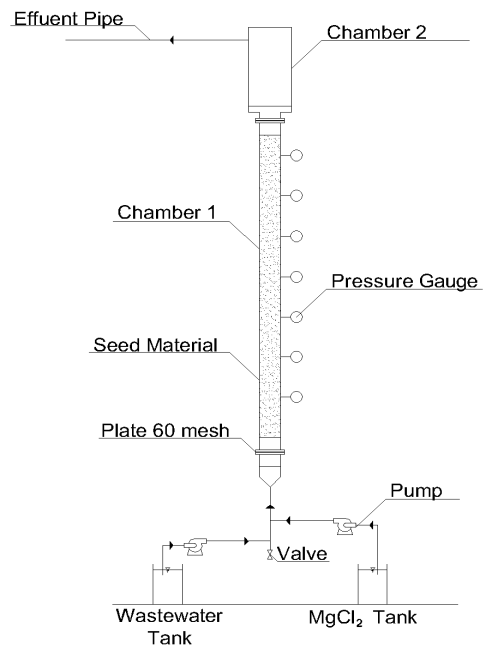

Fig. 1. Fluidized bed reactor.

\subsection{Experimental procedure}

Three tests were carried out in duplicate at three upflow velocities $(0.014,0.019$, and 0.024 $\mathrm{m} / \mathrm{s}$ ) for 70 minutes. Each upflow velocity was controlled and adjusted by using a flow adjuster in the diaphragm pump, at three flow rates $(1.6,2.2$, and $2.8 \mathrm{lpm})$. Each flow rate was divided between two inlets, wastewater, and $\mathrm{MgCl}_{2}$ solution, in a ratio of 1.5:1. The experiments were carried out on a laboratory scale and at room temperature.

\subsection{Analytical method}

The $\mathrm{pH}$ and flow rates were measured directly every 5 minutes and controlled. Samples (30 $\mathrm{mL}$ ) were taken from the effluent pipe every 5 minutes. The concentration of phosphates and ammonium was duplo analyzed every 5 minutes, while the fluoride concentration was Duplo analyzed before and after the test. For phosphate, ammonium, and fluoride analysis, the samples were filtered using a $22 \mu \mathrm{m}$ syringe and then analyzed by using Spectroquant ${ }^{\circledR}$ NOVA 60A. The seed material after every test was weighed. Then, the best result was analyzed by using scanning electron microscopy-energy diffraction X-rays (SEM-EDX, ZEISS EVO $^{\circledR}$ MA 10) to determine the crystals morphology and structure, and X-ray diffraction (XRD) (Philips Xpert Powder Diffractometer) to ensure the composition of the crystals formed.

\section{Results and discussion}

\subsection{Influence of upflow velocity on phosphate and ammonium concentration}

The upflow velocity was a factor that could promote the secondary nucleation or crystal growth of struvite. By increasing the upflow velocity, the density of the liquid is decreased, and a higher recirculation flow is induced [7]. A higher recirculation flow, which means higher mixing energy, should promote struvite crystallization based on struvite formation kinetics. Besides that, increasing the secondary nucleation or crystal growth can be done by increasing the reaction time. This test evaluates the comprehensive influence of the upflow 
velocity on the phosphate and ammonium concentration, which indicates struvite formation itself. Fig. 2 and 3 show respectively the results of phosphate and ammonium analysis every 5 minutes in every test.

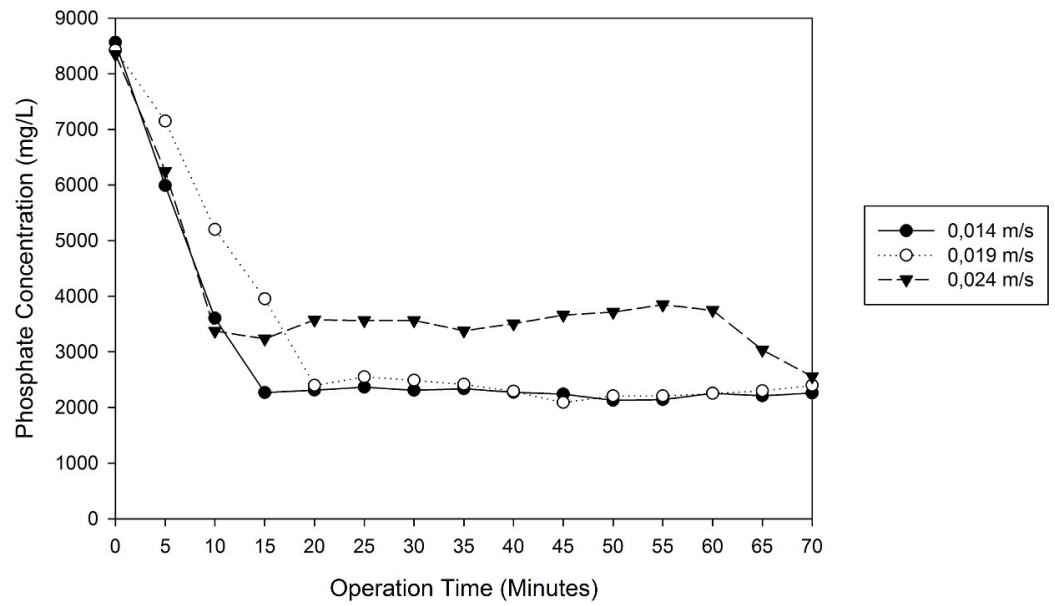

Fig. 2. Phosphate concentration at different upflow velocities.

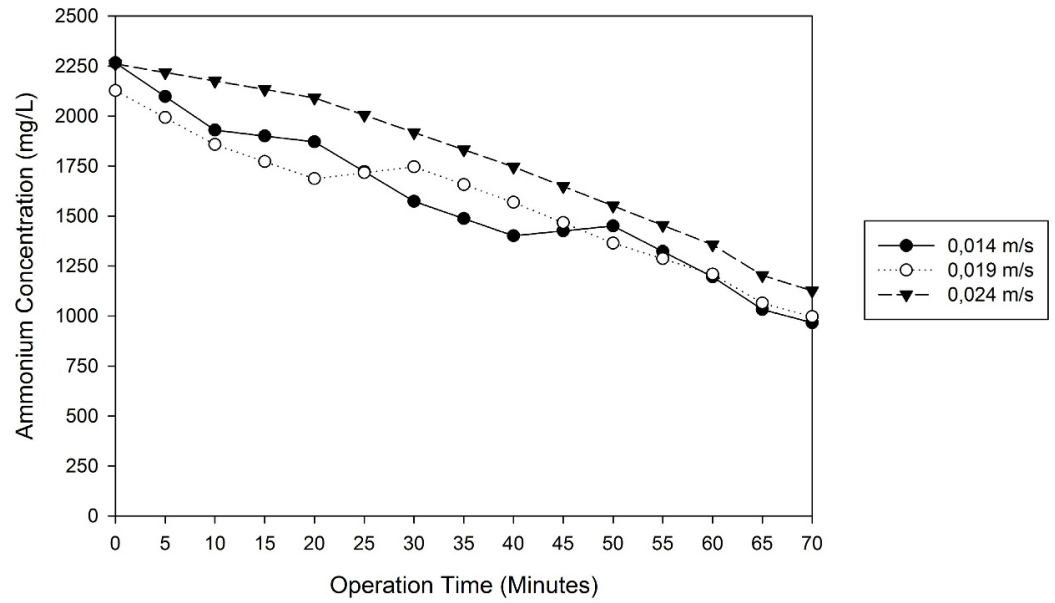

Fig. 3. Ammonium concentration at different upflow velocities.

Table 3. Recovery efficiency of phosphate and ammonium.

\begin{tabular}{|c|c|c|}
\hline \multirow{2}{*}{ Upflow velocity (m/s) } & \multicolumn{2}{|c|}{ Efficiency (\%) } \\
\cline { 2 - 3 } & Phosphate & Ammonium \\
\hline 0.014 & $73 \%$ & $57 \%$ \\
\hline 0.019 & $72 \%$ & $53 \%$ \\
\hline 0.024 & $70 \%$ & $50 \%$ \\
\hline
\end{tabular}

From Fig. 2, there is a condition where the concentration of phosphate decreased significantly, and after that, a constant concentration of phosphate was achieved. This 
condition showed that struvite crystals had already formed. The time needed to form struvite crystals from the supersaturated solution condition is the induction time [15]. The induction time for each test was 15,20 , and 10 minutes respectively at $0.014,0.019$, and $0.024 \mathrm{~m} / \mathrm{s}$. The induction time was different for each test. The induction time increased when the upflow velocity increased from 0.014 to $0.019 \mathrm{~m} / \mathrm{s}$ and decreased when the upflow velocity increased from 0.019 to $0.024 \mathrm{~m} / \mathrm{s}$. According to Tarrago [7], the induction time decreased with the increasing upflow velocity. Decreasing of the induction time was caused by increased the mixing energy and turbulence inside the reactor [11]. The recovery efficiency of phosphate and ammonium is detailed in Table 3. Table 3 shows that by decreasing the upflow velocity, a greater removal efficiency of phosphate and ammonium can be obtained. Decreasing the removal efficiency by increasing the upflow velocity was caused by the shorter detention time of the wastewater inside the reactor. The detention time for each upflow velocity was $3.066,2.230$, and 1.752 minutes respectively at 0.014 , 0.019 , and $0.024 \mathrm{~m} / \mathrm{s}$. This result corresponds with those of Guadie and Xia [24], who stated that a longer detention time of wastewater inside the reactor might cause increasing phosphate recovery efficiency. The phosphate recovery efficiency decreased by $1-2 \%$ while the ammonium decreased by $3-4 \%$ with every $0.005 \mathrm{~m} / \mathrm{s}$ increase of the upflow velocity. Based on these analysis, the reaction time has a greater effect than the upflow velocity in increasing the phosphate and ammonium recovery efficiency.

\subsection{Product characteristics}

The characteristics of the best configuration of FBR, at the upflow velocity of $0.014 \mathrm{~m} / \mathrm{s}$, were analyzed using SEM-EDX and XRD (Fig. 4). As shown in Fig. 4, the product (white colored) was adhered to the seed material, while the morphology of the product found at the outlet tank was elongated block.

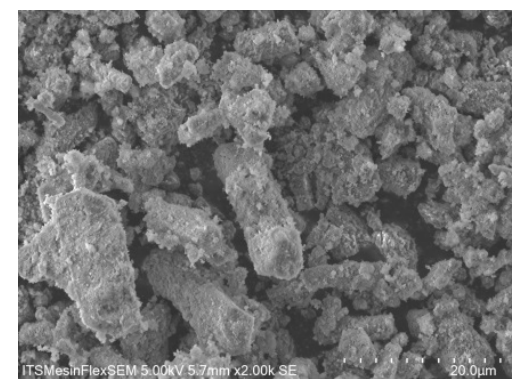

(a)

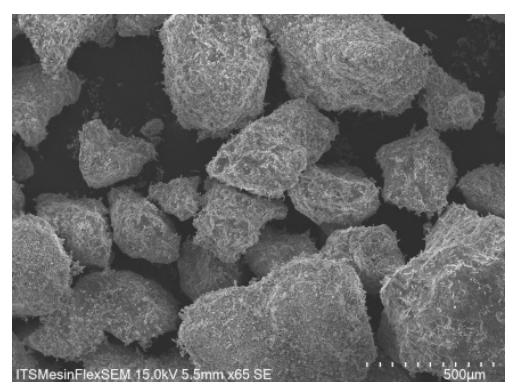

(b)

Fig. 4. Result of SEM analysis on the seed material and effluent crystals at $0.014 \mathrm{~m} / \mathrm{s}$ upflow velocity: (a) seed material at $65 \mathrm{x}$ magnification; (b) effluent crystals at $450 \mathrm{x}$ magnification.

Fig. 5 shows the result of the EDX analysis of the recovered product, which was mostly composed of $\mathrm{N}, \mathrm{O}, \mathrm{F}, \mathrm{Mg}, \mathrm{P}, \mathrm{Si}, \mathrm{O}$, and $\mathrm{Ca}$. The elements $\mathrm{N}, \mathrm{O}, \mathrm{P}$, and $\mathrm{Mg}$ are the constituent elements of struvite. Elements $\mathrm{F}$ and $\mathrm{Ca}$ are the impurities ions, while $\mathrm{Si}$ is the constituent element of the sand and wastewater. The XRD data from the laboratories were then analyzed using Match! Phase Identification Powder Diffraction. Fig. 6 shows the result of the XRD analysis on the seed material. From the XRD data, the product contains $60.2 \%$ struvite $\left(\mathrm{NH}_{4} \mathrm{PO}_{4} \mathrm{Mg} .6 \mathrm{H}_{2} \mathrm{O}\right), 19.2 \%$ fluorapatite $\left(\mathrm{Ca}_{5}\left(\mathrm{PO}_{4}\right)_{3} \mathrm{~F}\right), 10.3 \%$ brucite $\left(\mathrm{Mg}(\mathrm{OH})_{2}\right)$, and $10.4 \%$ fluorite $\left(\mathrm{CaF}_{2}\right)$. The fluorapatite formed because of the calcium contained in the wastewater. Fluorite was produced because of the fluoride and calcium from the wastewater that reacted together, while brucite was produced because of the magnesium that had not reacted with the phosphate. The impurities ions had a big impact on the product purity. 

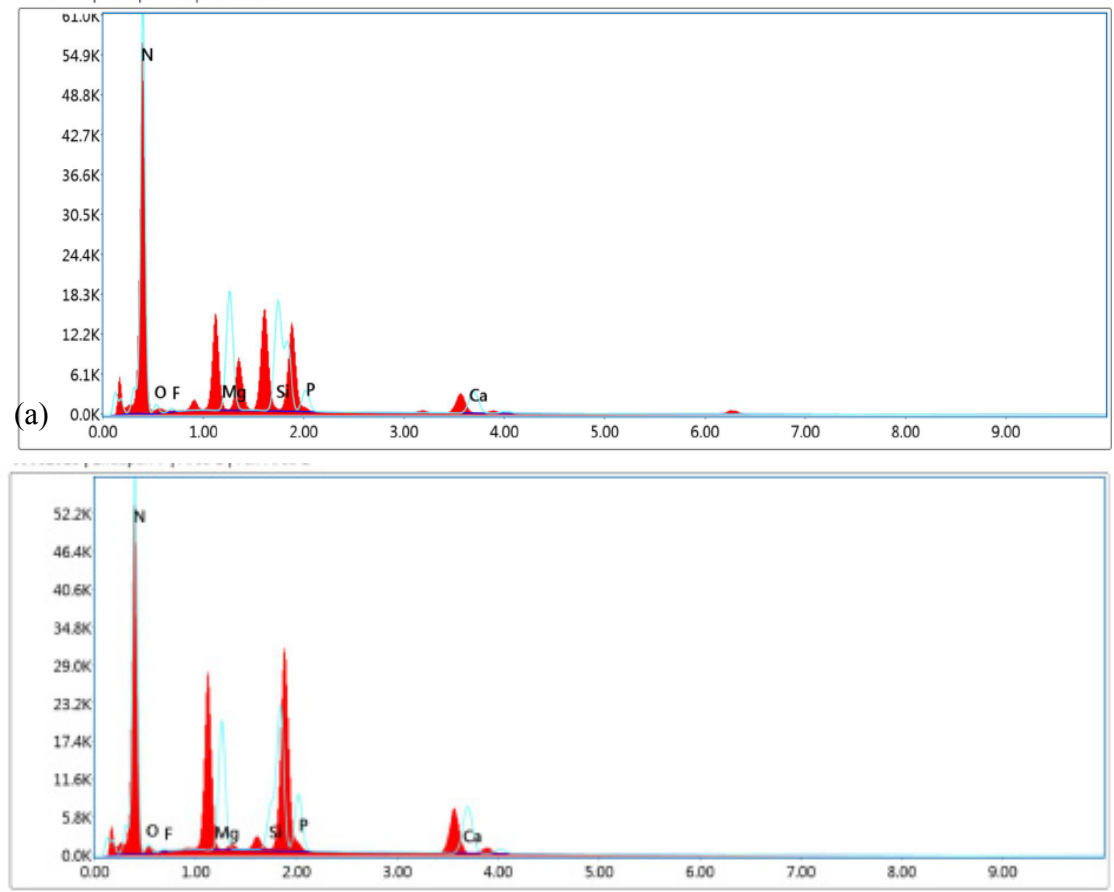

(b)

Fig. 5. Result of EDX analysis on the seed material and effluent crystals at $0.014 \mathrm{~m} / \mathrm{s}$ upflow velocity: (a) seed materials, (b) effluent crystals.

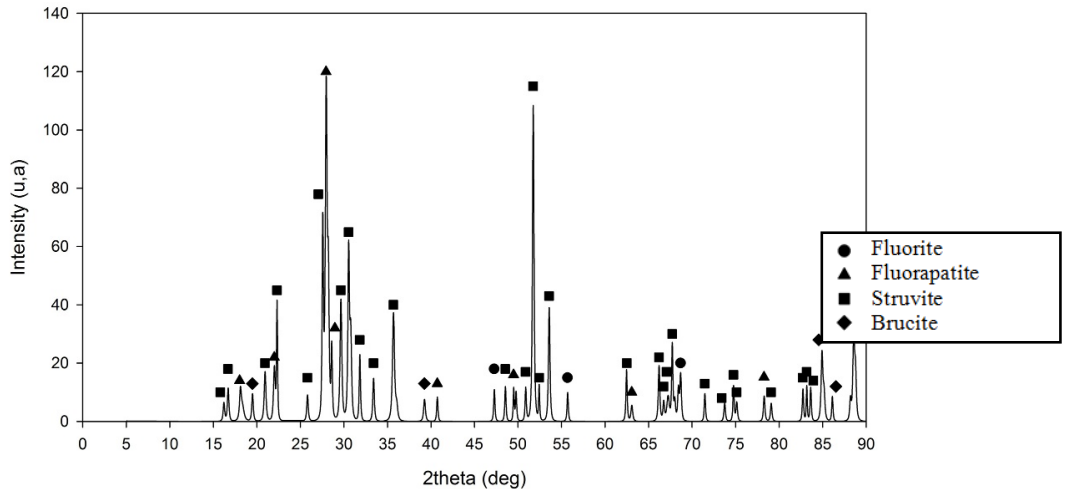

Fig. 6. Result of XRD analysis on seed material.

\section{Conclusions}

This research investigated the effect of upflow velocities on the efficiency of the phosphate and ammonium recovery when using a fluidized bed reactor, and the characteristics of the products that were recovered. The results showed that the highest efficiency of phosphate and ammonium recovery was $73 \%$ and $57 \%$ respectively, when using a $0.014 \mathrm{~m} / \mathrm{s}$ upflow velocity. Increasing the upflow velocity at intervals of $0.005 \mathrm{~m} / \mathrm{s}$ could decrease the efficiency of phosphate recovery by $1-2 \%$ and ammonium by $3-4 \%$. SEM-EDX analysis showed that the product attached to the seed material contained $\mathrm{N}, \mathrm{P}, \mathrm{Mg}, \mathrm{O}, \mathrm{Ca}, \mathrm{F}$, and $\mathrm{Si}$ 
as the main constituent elements. Furthermore, the product recovered contained $60.2 \%$ of struvite, which was caused by impurities ions that produced another compound that made the morphology of the product elongated cubes with non-smooth surfaces. Therefore better pre-treatment should be implemented to provide higher purity struvite.

This research was supported by the Ministry of Research, Technology and Higher Education of the Republic of Indonesia through Research Grant Scheme 2018.

\section{References}

1. K.H. Sabry, Fertilizer Tech. 1 (2015)

2. Warmadewanthi, E.S. Pandebesie, W. Herumurti, A.Y. Bagastyo, Misbachul. Chem Eng. J. 56 (2017)

3. D.L. Corell, J. of Env. 27 (1998)

4. C.F. Masson, Biology of fresh water pollution (Longman Publishers, Singapore, 1991)

5. F.A. Khan, A.A. Ansari. Bot. Rev. 71 (2005)

6. M. Senante, F.H. Sancho, R.S. Ambio 40 (2010)

7. E. Tarrago, Chem. Eng. J. 302 (2016)

8. M.M. Rahman, Arabian J. of Chem. 7 (2014)

9. M.S. Rahaman, N. Ellis, D.S. Mavinic, Water Sci. Tech. 57 (2008)

10. N. Bouropoulos, P.G. Koutsouko, J. of Crystal Growth 213 (2000)

11. M.I.H. Bhuiyan, D.S. Mavinic, F.A Kochl, Water Sci. Tech. 57 (2008)

12. K. Shimamura, Water Sci. Tech. 48 (2003)

13. A. Adnan, M. Dastur, D.S. Mavinic, F.A. Koch, Env. Eng. J. 3 (2003)

14. S.A. Myerson, Handbook of industrial crystallization (Butterworth-Heinemann, Oxford, 2002)

15. P. Tang, H.Ma, Int. J. of Env. Protection and Policy 4 (2016)

16. F.A. Koch, S. Mavinic, N. Yonemitsu, Fluidized bed wastewater treatment, United States Patent US 7622047 B2 (2009)

17. Y. Ueno, M. Fuji, Env. Tech. 22 (2001)

18. W.R. Abma, W. Driessen, R. Haarhuis, Water Sci. and Tech. 61 (2010)

19. W. Moerman, M. Carballa, A. Vandekerckhove, Water Res. 43 (2009)

20. K.N. Ohlinger, T.M. Young, E.D. Schroeder, J. of Env. Eng. 126 (2000)

21. K.E. Bowers, P.W. Westerman, Transactions of the ASAE 48, 3 (2005)

22. L. Qin, L.H. Zhenli, P.J. Stofella, App. and Env. Soil Sci. 2012 (2012)

23. A. Johari, R. Taib, J. of Chem. and Natural Res. Eng. 2 (2007)

24. A. Guadie, S. Xia, Proc. of 12th Symposium on Sustainable Water Resources Development (2012) 